\title{
Patients' knowledge, attitudes and practices regarding antibiotic use at a regional hospital in KwaZulu-Natal, South Africa 2017
}

\author{
K Ramchurren $^{\mathrm{a} *}$ (D), Y Balakrishna ${ }^{\mathrm{b}}$ (D) and S Mahomed ${ }^{\mathrm{c}}$ (D) \\ ${ }^{a}$ School of Nursing and Public Health, University of KwaZulu-Natal, Durban, South Africa \\ ${ }^{b}$ Biostatistics Unit, South African Medical Research Council, Durban, South Africa \\ 'School of Laboratory Medicine and Medical Sciences, University of KwaZulu-Natal, Durban, South Africa \\ *Corresponding author, email: kershal86@gmail.com
}

Background: Antibiotic resistance is a major public-health problem globally and inappropriate antibiotic use is being increasingly recognised as the main force driving this resistance. Communities can contribute to the reduction of antibiotic resistance by using antibiotics appropriately and as prescribed. The purpose of this study was to assess the knowledge, attitudes and practices of patients regarding antibiotic use at a regional hospital in South Africa.

Method: An observational analytic, cross-sectional study was conducted at Prince Mshiyeni Memorial Hospital between May and June 2017. A validated questionnaire consisting of closed-ended questions was administered to outpatients. Patients' responses were scored and categorised as poor or good for knowledge, attitude and practice.

Results: A total of 386 patients were interviewed. Only 205 (53\%) patients had a good level of knowledge. Although 270 (70\%) patients knew that antibiotics are indicated for the treatment of bacterial infections, 211 (55\%) patients incorrectly thought that antibiotics are also used to treat viral infections. Only $168(44 \%)$ patients were aware of the resistance associated with overusing antibiotics. With regard to patients' attitudes, 164 (42\%) patients believed that taking antibiotics for the common cold helped them to recover faster and 178 (46\%) patients expected the doctor to prescribe more than one antibiotic for a severe cold. Overall, 157 patients $(40 \%)$ reported having shared antibiotics with friends or family. Patients with good knowledge were six times more likely to have good antibiotic practices (OR 5.8; 95\% Cl 0.3-10.6; $p<0.001$ ).

Conclusion: A well-planned education programme for the public should be undertaken to improve the knowledge and uses of antibiotics among patients.

Keywords: attitude, knowledge, practice, resistance

\section{Introduction}

Antibiotics revolutionised the platform for medical developments and are indispensable around the world. Triumphs in modern medicine such as cancer chemotherapy and surgery would have been impossible without the use of effective treatment for bacterial infections. ${ }^{1}$ However, globally, several previously susceptible bacteria have developed resistance to antibiotics. ${ }^{2}$ The World Health Organization defines antibiotic resistance as the ability of bacteria to resist the effects of antibiotic treatment to which they were once sensitive. ${ }^{3}$ Antibiotic resistance has become a serious threat to public health.

Antibiotic resistance has resulted in prolonged illness and hospital stays due to the challenges in treating infections and resulting increased mortality and morbidity has financial implications for the individual as well as the healthcare system. ${ }^{4}$ The World Health Organization has referred to the twentky-first century as the post-antibiotic era in which minor injuries and common infections can threaten the lives and the general well-being of all populations. ${ }^{4}$

South Africa is faced with an increasing burden of antibiotic resistance $^{5}$ and a collaborative effort between effective antibiotic use and appropriate infection control is needed to curb the spread of these resistant organisms. One of the objectives of the South African Antibiotic Stewardship Program is to promote rational use of antibiotics and antibiotic education for healthcare workers and the public. ${ }^{6}$ In response to the global health risk that antibiotic resistance poses, the National Department of
Health developed the Antimicrobial Resistance National Strategy Framework with the aim of reducing further increases in resistant bacterial infections and improving patient outcomes. ${ }^{7}$ This framework emphasises communication with the public to create antibiotic awareness, and patient education on the dangers associated with inappropriate use of antibiotics. ${ }^{7}$

Patients' knowledge of and attitude towards antibiotics has been shown to influence their use of antibiotics. ${ }^{8,9}$ Misuse of antibiotics by patients plays an important role in driving the emergence and dissemination of bacterial resistance. ${ }^{8}$ Understanding patients' knowledge and practices concerning antibiotics can help to mitigate antibiotic resistance and sustain antibiotic effectiveness.

There is currently no research in South Africa on patients' knowledge of antibiotics. The aim of this study was to assess patients' knowledge, attitude and practice regarding antibiotic use amongst outpatients at a regional hospital in KwaZulu-Natal.

\section{Methods}

\section{Study setting}

The study was conducted at Prince Mshiyeni Memorial Hospital (PMMH) located in Ethekwini district, KwaZulu-Natal. This 1 200bed hospital offers both regional and district level services to an estimated population of two million. Approximately 600 patients are seen in the Medical Outpatient Department (MOPD) daily. 


\section{Study population and sample frame}

The study population included all adult patients attending the MOPD. Patients older than 60 years or patients who took antibiotics as part of their chronic treatment were excluded.

A systematic random sampling approach was used to select the sample. A practical sample size of 30 patients was chosen to be interviewed per day. A sample fraction was calculated based on the average number of patients seen daily. The selection of the first patient was random. Thereafter every twentieth patient was enrolled. This ensured an even spread of participants throughout the day.

\section{Sample size}

A sample size of 384 was estimated to be effective for this study. This sample size produced a two-sided $95 \%$ confidence interval with a precision of $\pm 8 \%$ when the actual proportion was near $50 \%$. The calculation is based on normal distribution and the assumption that there would be more than 30 participants.

\section{Study design and questionnaire development}

This was an observational analytic cross-sectional study. The questionnaire, which comprised four parts, was adapted from previous studies ${ }^{10-12}$ and modified to suit the local population. Part 1 of the questionnaire pertained to the sociodemographic

Table 1: Sociodemographic characteristics of patients at the Medical Outpatient Department at Prince Mshiyeni Memorial Hospital, 2017

\begin{tabular}{|c|c|c|}
\hline Characteristic & Frequency $(n=386)$ & Percentage (\%) \\
\hline \multicolumn{3}{|l|}{ Age: } \\
\hline $18-30$ & 71 & 18.4 \\
\hline $31-40$ & 67 & 17.4 \\
\hline $41-50$ & 102 & 26.4 \\
\hline $51-60$ & 146 & 37.8 \\
\hline \multicolumn{3}{|l|}{ Gender: } \\
\hline Male & 203 & 52.6 \\
\hline Female & 183 & 47.4 \\
\hline \multicolumn{3}{|l|}{ Race: } \\
\hline Black & 353 & 91.5 \\
\hline White & 16 & 4.2 \\
\hline Indian & 9 & 2.3 \\
\hline Coloured & 8 & 2.1 \\
\hline \multicolumn{3}{|l|}{ Education: } \\
\hline No formal education & 29 & 7.5 \\
\hline Primary school & 127 & 32.9 \\
\hline Secondary school & 208 & 53.9 \\
\hline Tertiary & 22 & 5.7 \\
\hline \multicolumn{3}{|l|}{ Monthly income: } \\
\hline$<\mathrm{R} 500$ & 48 & 12.4 \\
\hline R500-R1 399 & 131 & 33.9 \\
\hline R1 400-R10 000 & 92 & 23.8 \\
\hline$>\mathrm{R} 10000$ & 3 & 0.8 \\
\hline Do not wish to answer & 112 & 29.0 \\
\hline \multicolumn{3}{|l|}{ Marital status: } \\
\hline Single & 119 & 30.8 \\
\hline Married & 192 & 49.7 \\
\hline Widowed & 69 & 17.9 \\
\hline Divorced & 6 & 1.6 \\
\hline
\end{tabular}

characteristics of the patients. Part 2 of the questionnaire consisted of 13 statements to assess the patients' knowledge of antibiotics. The aspects assessed were the use of antibiotics (five statements), identification of antibiotics (five statements) and dangers of using antibiotics (three statements). Part 3 of the questionnaire consisted of seven statements that assessed the attitudes of patients towards antibiotic use and part 4 consisted of seven statements that assessed patients' practices regarding antibiotics. A three-point Likert scale ranging from 'agree', 'unsure' to 'disagree' was used to assess patients' responses. One mark was awarded for each correct answer and zero for each incorrect or unsure answer. Each of the domains assessed was categorised as poor or good based on the score achieved. In the knowledge section, patients with scores of 7 and above were categorised as having good knowledge. In the attitude and practice sections, patients with scores of 4 and above were classified as having good attitudes and good practice. The questionnaire was designed in two language versions: English and isiZulu, the latter being the predominant language spoken in KwaZulu-Natal.

Face and content validation of the questionnaire was done by three senior hospital staff members (hospital medical manager, clinical manager of Medical Outpatient Department, and a senior pharmacist). Reliability of the questionnaire was assessed by calculating the Cronbach's a. The results showed good consistency yielding an a of 0.732 for the knowledge statements, 0.814 for the practice statements and 0.9 for the attitude statements.

\section{Data collection and analysis}

The interview with the patient was conducted in a private consulting room by the researcher and a designated nurse. Written informed consent was obtained before participation in the study.

Data were analysed using Stata version 14 (StataCorp, College Station, TX, USA). Pearson's chi-square or Fisher's exact test was used to test associations between categorical variables. Continuous variables were described as means (with standard deviations), and tested for differences using ANOVA. A multivariate logistic regression was used to determine the association between demographic variables and knowledge, attitude and practice scores. Results were considered significant for $p<0.05$.

\section{Ethical considerations}

Gatekeeper permission was obtained from the hospital medical manager and the KwaZulu-Natal Provincial Health Research and Ethics Committee. The research was approved by the Humanities and Social Sciences Research Ethics Committee of the University of KwaZulu-Natal (HSS/1063/016M).

\section{Results}

\section{Sociodemographic characteristics}

As indicated in Table 1, the sample consisted of 386 patients of whom 203 (53\%) were males. The majority of patients were over the age of 40 years $(n=248,64 \%)$ and just over half the study population ( $n=208,54 \%$ ) had completed secondary school.

\section{Knowledge of antibiotics}

Overall, 205 (53\%) patients were classified as having good knowledge based on the scoring (Table 2). Regarding the use of antibiotics, although 270 (70\%) patients identified that antibiotics are used for treating bacterial infections, 211 (55\%) of 
Table 2: Patients' knowledge of antibiotics at Prince Mshiyeni Memorial Hospital 2017

\begin{tabular}{|c|c|c|c|c|}
\hline \multirow[b]{2}{*}{ Statement } & Agree & Unsure & Disagree & Total \\
\hline & $n(\%)$ & $n(\%)$ & $n(\%)$ & $n(\%)$ \\
\hline \multicolumn{5}{|l|}{ Use of antibiotics: } \\
\hline $\begin{array}{l}\quad \text { Antibiotics are } \\
\text { medicines that } \\
\text { treat bacterial } \\
\text { infections }\end{array}$ & $270(70)$ & $76(20)$ & $40(10)$ & $386(100)$ \\
\hline $\begin{array}{l}\text { Antibiotics are } \\
\text { used to treat viral } \\
\text { infections }\end{array}$ & $211(55)$ & $69(18)$ & $106(27)$ & $386(100)$ \\
\hline $\begin{array}{l}\text { Antibiotics treat } \\
\text { all infections }\end{array}$ & $168(44)$ & $67(17)$ & $151(39)$ & $386(100)$ \\
\hline \begin{tabular}{l}
\multicolumn{1}{c}{ Antibiotics } \\
relieve pain and \\
inflammation
\end{tabular} & $106(27)$ & $62(16)$ & $218(57)$ & $386(100)$ \\
\hline $\begin{array}{l}\text { Antibiotics treat } \\
\text { fevers }\end{array}$ & $153(40)$ & $73(19)$ & $160(41)$ & $386(100)$ \\
\hline \multicolumn{5}{|c|}{ Identification of antibiotics: } \\
\hline $\begin{array}{l}\text { Penicillin is an } \\
\text { antibiotic }\end{array}$ & $246(64)$ & $101(26)$ & $39(10)$ & $386(100)$ \\
\hline $\begin{array}{l}\text { Aspirin is an } \\
\text { antibiotic }\end{array}$ & $32(8)$ & $57(15)$ & $297(77)$ & $386(100)$ \\
\hline $\begin{array}{l}\quad \text { A cough } \\
\text { mixture is an } \\
\text { antibiotic }\end{array}$ & $32(8)$ & $45(12)$ & $309(80)$ & $386(100)$ \\
\hline $\begin{array}{l}\text { The flu vaccine } \\
\text { is an antibiotic }\end{array}$ & $138(36)$ & $121(31)$ & $127(33)$ & $386(100)$ \\
\hline $\begin{array}{l}\text { All injections are } \\
\text { antibiotics only }\end{array}$ & $69(18)$ & $117(30)$ & $200(52)$ & $386(100)$ \\
\hline \multicolumn{5}{|c|}{ Dangers of using antibiotics: } \\
\hline \begin{tabular}{l}
\multicolumn{1}{l}{ Overuse of } \\
antibiotics make \\
them less effective \\
over time
\end{tabular} & $168(44)$ & $152(39)$ & $66(17)$ & $386(100)$ \\
\hline $\begin{array}{l}\text { Antibiotic } \\
\text { resistance is due } \\
\text { to unnecessary } \\
\text { use of antibiotics }\end{array}$ & $150(39)$ & $146(38)$ & $90(23)$ & $386(100)$ \\
\hline $\begin{array}{l}\text { Antibiotics have } \\
\text { no side effects }\end{array}$ & $76(20)$ & 75 (19) & $235(61)$ & $386(100)$ \\
\hline
\end{tabular}

the patients also thought that antibiotics are used to treat viral infections. In terms of the identification of antibiotics, only 138 (33\%) patients knew that the influenza vaccine was not an antibiotic. Regarding the dangers of using antibiotics, 152 (39\%) patients indicated they were unsure about the effectiveness of overusing antibiotics and $146(38 \%)$ patients were unsure about the causes of antibiotic resistance. Only 235 (61\%) patients believed that antibiotics have no side effects.

In the multivariate analysis (Table 3 ), patients in the age category 51-60 years were less likely to have good knowledge of antibiotics compared with younger patients (odds ratio $(\mathrm{OR}=0.3$; $95 \% \mathrm{Cl} 0.1-0.9 ; p=0.025$ ). Patients with a secondary level of education were almost six times more likely to have good knowledge compared with patients with no formal education (OR 5.5; $95 \% \mathrm{Cl} 1.6-18.8 ; p=0.007$ ).

\section{Attitude towards antibiotics}

Just over half the sample $(n=211,55 \%)$ of patients were classified as having good attitudes towards antibiotic use. Some 178 (46\%) patients believed the doctor must prescribe more than one antibiotic in cases of severe influenza (Table 4). Approximately one-third of patients $(n=131,34 \%)$ requested antibiotics even if the doctor had advised against their use. Two hundred and forty-nine $(65 \%)$ patients believed that antibiotics must be taken according to the doctor's or pharmacist's instructions.

In the bivariate analysis, patients in the age categories $41-50$ years $(\mathrm{OR}=0.5 ; 95 \% \mathrm{Cl} 0.3-1.0 ; p=0.047)$ and $51-60$ years (OR $=0.4 ; 95 \% \mathrm{Cl} 0.2-0.7 ; p=0.002$ ) were less likely to have good attitudes towards antibiotic use compared with younger patients, but this association was not significant in the multivariate analysis (Table 5). Patients with good knowledge of antibiotics were almost four times more likely to have good attitudes toward antibiotic use compared with patients with poor knowledge $(\mathrm{OR}=3.8 ; 95 \% \mathrm{Cl} 2.2-6.8 ; p<0.001)$.

\section{Antibiotic practices}

Two hundred and seventy-three (71\%) patients reported that they take antibiotics according to the directions on the label (Table 6). Almost half the sample $(n=181,48 \%)$ reported that they stop taking their antibiotic when they feel better, and

Table 3: Sociodemographic characteristics associated with good knowledge of antibiotics amongst patients at Prince Mshiyeni Memorial Hospital 2017

\begin{tabular}{|c|c|c|c|c|c|}
\hline Factor & Category & Unadjusted OR (95\% Cl) & $p$-value & Adjusted OR (95\% Cl) & $p$-value \\
\hline \multirow[t]{4}{*}{ Age } & $18-30$ & Reference & & Reference & \\
\hline & $31-40$ & $0.6(0.2-1.2)$ & 0.126 & $0.9(0.3-2.4)$ & 0.773 \\
\hline & $41-50$ & $0.3(0.1-0.5)$ & $<0.001$ & $0.4(0.1-1.0)$ & 0.052 \\
\hline & $51-60$ & $0.2(0.1-0.4)$ & $<0.001$ & $0.3(0.1-0.9)$ & 0.025 \\
\hline \multirow[t]{2}{*}{ Gender } & Male & Reference & & Reference & \\
\hline & Female & $0.9(0.7-1.5)$ & 0.969 & $1.2(0.7-2.1)$ & 0.460 \\
\hline \multirow[t]{4}{*}{ Education } & No formal & Reference & & Reference & \\
\hline & Primary & $1.3(0.5-3.6)$ & 0.553 & $1.6(0.5-5.2)$ & 0.464 \\
\hline & Secondary & $8.6(3.4-22.2)$ & $<0.001$ & $5.5(1.6-18.8)$ & 0.007 \\
\hline & Tertiary & $1^{\mathrm{a}}$ & & $1^{\mathrm{a}}$ & \\
\hline \multirow[t]{4}{*}{ Income } & $<\mathrm{R} 500$ & Reference & & Reference & \\
\hline & R500-R1 399 & $1.1(0.6-2.1)$ & 0.807 & $0.9(0.4-1.9)$ & 0.799 \\
\hline & R1 400-R10 000 & $2.7(1.3-5.4)$ & 0.008 & $1.0(0.4-2.5)$ & 0.907 \\
\hline & $>\mathrm{R} 10000$ & $2.6(0.2-30.3)$ & 0.453 & $1^{\mathrm{a}}$ & \\
\hline
\end{tabular}

apredicts good knowledge perfectly and therefore was not included in the model. 
Table 4: Patients' attitudes towards antibiotic use at Prince Mshiyeni Memorial Hospital 2017

\begin{tabular}{l|c|c|c|c|}
\hline & Agree & Unsure & Disagree & Total \\
\cline { 2 - 5 } & $n(\%)$ & $n(\%)$ & $n(\%)$ & $n(\%)$ \\
\hline $\begin{array}{l}\text { Statement } \\
\text { I always need an } \\
\text { antibiotic when I } \\
\text { develop a sore } \\
\text { throat }\end{array}$ & $142(37)$ & $34(9)$ & $210(54)$ & $386(100)$ \\
\hline $\begin{array}{l}\text { Antibiotics help } \\
\text { me recover from a } \\
\text { cold much quicker }\end{array}$ & $164(42)$ & $37(10)$ & $185(48)$ & $386(100)$ \\
\hline $\begin{array}{l}\text { I always expect the } \\
\text { doctor to prescribe } \\
\text { an antibiotic when } \\
\text { I feel ill }\end{array}$ & $128(33)$ & $36(9)$ & $222(58)$ & $386(100)$ \\
\hline $\begin{array}{l}\text { I request } \\
\text { antibiotics even if } \\
\text { the doctor has } \\
\text { advised against it }\end{array}$ & $131(34)$ & $38(10)$ & $217(56)$ & $386(100)$ \\
\hline $\begin{array}{l}\text { The doctor must } \\
\text { prescribe more } \\
\text { than one antibiotic } \\
\text { if I have severe flu }\end{array}$ & $178(46)$ & $54(14)$ & $154(40)$ & $386(100)$ \\
\hline $\begin{array}{l}\text { If I don't take } \\
\text { antibiotics as } \\
\text { instructed by my } \\
\text { doctor or } \\
\text { pharmacist, the } \\
\text { antibiotic may not } \\
\text { help me the next } \\
\text { time I use it }\end{array}$ & $249(65)$ & $61(15)$ & & \\
\hline $\begin{array}{l}\text { I prefer to be able } \\
\text { to buy antibiotics } \\
\text { from the pharmacy } \\
\text { without a doctor's } \\
\text { prescription. }\end{array}$ & $165(43)$ & $56(14)$ & $165(43)$ & $386(100)$ \\
\hline & & & \\
\hline
\end{tabular}

200 (52\%) reported that they stop taking their antibiotic if they feel it is not helping them. One hundred and fifty-seven patients $(41 \%)$ reported sharing antibiotics with friends and family if they needed them. Overall, $230(60 \%)$ patients were classified as having good antibiotic practices.
In the bivariate analysis age, income and education were significantly associated with good antibiotic practices but these associations were not significant in the multivariate analysis (Table 7). Patients with good knowledge were six times more likely to have good antibiotic practices (OR 5.8; $95 \% \mathrm{Cl} 3.1-$ 10.6; $p<0.001$ ).

\section{Discussion}

This study has identified important gaps in patients' knowledge of antibiotics. The lack of knowledge on the rationale for antibiotics is not unique to South Africa. The proportion of patients who thought that antibiotics are effective for viral infections $(55 \%)$ is comparable with a survey conducted in England $(56 \%) .{ }^{13}$ The low proportion of patients who believed antibiotic resistance is due to the unnecessary use of antibiotics may be because patients are not well informed concerning the term 'antibiotic resistance'. The World Health Organization has identified a reduction in the unnecessary use of antibiotics as a key issue for public involvement. ${ }^{14}$

Several studies have revealed that patients' expectations are important determinants of antibiotic prescribing. ${ }^{15}$ In this study, only $33 \%$ of patients expected antibiotic treatment for common cold symptoms, which is lower than the $44 \%$ reported from a survey in Windhoek, Namibia. ${ }^{16}$ In contrast, a higher proportion (46\%) of patients in our study expected the doctor to prescribe additional antibiotics in cases of severe influenza than the $41 \%$ of patients recorded in the Namibian study. The decision to prescribe antibiotics can be influenced by the doctor-patient relationship, in which the doctor may want to satisfy the patient's request even though the doctor feels that an antibiotic is unnecessary. ${ }^{15}$ Under the circumstances, the doctor patient-patient relationship in South Africa is generally vulnerable for patients as they are more inclined to rely on the doctor's decision than question it.

Nearly half our sample (47\%) reported discontinuing antibiotic therapy when they began to feel better. Several recent studies have demonstrated that shorter-course antibiotic regimens are also effective although this new research is limited to

Table 5: Sociodemographic characteristics associated with good attitudes towards antibiotic use amongst patients at Prince Mshiyeni Memorial Hospital 2017

\begin{tabular}{|c|c|c|c|c|c|}
\hline Factor & Category & Unadjusted OR (95\% Cl) & $p$-value & Adjusted OR (95\% Cl) & $p$-value \\
\hline \multirow[t]{4}{*}{ Age } & $18-30$ & Reference & & Reference & \\
\hline & $31-40$ & $0.7(0.3-1.3)$ & 0.254 & $0.9(0.4-2.3)$ & 0.913 \\
\hline & $41-50$ & $0.5(0.3-1.0)$ & 0.047 & $1.6(0.7-4.1)$ & 0.281 \\
\hline & $51-60$ & $0.4(0.2-0.7)$ & 0.002 & $0.8(0.3-2.0)$ & 0.651 \\
\hline \multirow[t]{2}{*}{ Gender } & Male & Reference & & Reference & \\
\hline & Female & 0.9 & 0.535 & $0.7(0.3-1.1)$ & 0.130 \\
\hline \multirow[t]{4}{*}{ Education } & No formal & Reference & & Reference & \\
\hline & Primary & $0.8(0.3-1.8)$ & 0.589 & $0.6(0.2-1.8)$ & 0.385 \\
\hline & Secondary & $2.1(1.0-4.6)$ & 0.065 & $0.9(0.3-2.8)$ & 0.869 \\
\hline & Tertiary & $4.2(1.2-14.4)$ & 0.023 & $1^{\mathrm{a}}$ & \\
\hline \multirow[t]{4}{*}{ Income } & $<$ R500 & Reference & & Reference & \\
\hline & R500-R1 399 & $0.9(0.5-1.8)$ & 0.802 & $0.8(0.4-1.7)$ & 0.553 \\
\hline & R1 400-R10 000 & $1.8(0.9-3.6)$ & 0.113 & $0.9(0.4-2.3)$ & 0.994 \\
\hline & $>\mathrm{R} 10000$ & $1^{\mathrm{a}}$ & & $1^{\mathrm{a}}$ & \\
\hline \multirow[t]{2}{*}{ Knowledge } & Poor & Reference & & & \\
\hline & Good & $4.0(2.6-6.1)$ & $<0.001$ & $3.8(2.2-6.8)$ & $<0.001$ \\
\hline
\end{tabular}

apredicts good attitude perfectly and therefore was not included in the study. 
Table 6: Patients' practices regarding antibiotic use at Prince Mshiyeni Memorial Hospital 2017

\begin{tabular}{l|c|c|c|c|}
\hline & Agree & Unsure & Disagree & Total \\
\cline { 2 - 5 } & $n(\%)$ & $n(\%)$ & $n(\%)$ & $n(\%)$ \\
\hline $\begin{array}{l}\text { Statement } \\
\text { I take my } \\
\text { antibiotics } \\
\text { according to } \\
\text { directions on the } \\
\text { label }\end{array}$ & $273(71)$ & $10(2)$ & $103(27)$ & $386(100)$ \\
\hline $\begin{array}{l}\text { I take extra } \\
\text { antibiotic pills if } \\
\text { my condition } \\
\text { worsens }\end{array}$ & $145(37)$ & $3(1)$ & $238(62)$ & $386(100)$ \\
\hline $\begin{array}{l}\text { I stop taking my } \\
\text { antibiotic when I } \\
\text { start feeling better }\end{array}$ & $181(48)$ & $4(1)$ & $201(52)$ & $386(100)$ \\
\hline $\begin{array}{l}\text { I stop taking my } \\
\text { antibiotic if I } \\
\text { experience side } \\
\text { effects without } \\
\text { consulting a } \\
\text { doctor or } \\
\text { pharmacist }\end{array}$ & $195(51)$ & $7(2)$ & $184(48)$ & $386(100)$ \\
\hline $\begin{array}{l}\text { I stop taking my } \\
\text { antibiotic if I feel it } \\
\text { is not helping me }\end{array}$ & $200(52)$ & $7(2)$ & $179(46)$ & $386(100)$ \\
\hline $\begin{array}{l}\text { I share antibiotics } \\
\text { with friends and } \\
\text { family if they need } \\
\text { them }\end{array}$ & $157(41)$ & $3(1)$ & $226(58)$ & $386(100)$ \\
\hline $\begin{array}{l}\text { I reserve } \\
\text { antibiotics to self- } \\
\text { medicate for future } \\
\text { use }\end{array}$ & $109(28)$ & $3(1)$ & $274(71)$ & $386(100)$ \\
\hline
\end{tabular}

the treatment of community-acquired pneumonia, urinary tract infections, tonsillitis and intra-abdominal infections. ${ }^{17-19}$ Current international recommendations are that patients must complete their antibiotic course, regardless of clinical symptoms. ${ }^{20}$ However, these recommendations have come under scrutiny as the ideology that stopping antibiotic treatment before the course is complete will lead to antibiotic resistance was not evidence-based and more research is warranted in this area. ${ }^{21}$

Education was associated with good knowledge and good attitudes. Similar observations were also reported in studies conducted in Malaysia, Palestine and Hong Kong, which demonstrated that patients with higher levels of education were more likely to have good antibiotic knowledge and positive attitudes towards antibiotic usage. ${ }^{11,22,23}$ An epidemiological study in Scotland reported that education (as measured by an IQ-type test) in childhood predicts substantial differences in adult morbidity and mortality. ${ }^{24}$ One possible explanation for these results is that education enhances an individual's maintenance of his/her own health because it represents reasoning, learning and problem-solving skills useful in the prevention and treatment of disease and injury. ${ }^{24}$ In addition, higher education results in jobs with better income and therefore improved health through diet and lifestyles that are affordable and sustainable.

The age of the patient was associated with good antibiotic knowledge in the current study, with older patients having significantly less knowledge than younger patients. Antibiotic resistance has recently become a priority on health agendas and it is likely that younger patients may be more aware of this concept through messages in the media, particularly through online and social media platforms. ${ }^{25}$ However, in the study in Malaysia, older patients were more likely to have better knowledge of antibiotics and other studies have found no association between the age of the patient and the patient's knowledge, suggesting a need for further investigation of this association. ${ }^{22,23}$

Our finding that good knowledge of antibiotics predicts good attitude and practice regarding antibiotics has also been reported in research from Palestine. ${ }^{22}$ Knowledge-attitudebehaviour models have theorised that knowledge is one of several determinants of attitude. ${ }^{26}$ Increased knowledge is likely to lead to attitudes that are more stable and resistant to negative changes. ${ }^{27}$ Some mechanisms underlying the association of knowledge with attitude and practices conceptualise that greater knowledge predictably leads to enhanced

Table 7: Sociodemographic characteristics associated with good practices regarding antibiotic use amongst patients at Prince Mshiyeni Memorial Hospital 2017

\begin{tabular}{|c|c|c|c|c|c|}
\hline Factor & Category & Unadjusted OR (95\% Cl) & $p$-value & Adjusted OR (95\% Cl) & $p$-value \\
\hline \multirow[t]{4}{*}{ Age } & $18-30$ & Reference & & Reference & \\
\hline & $31-40$ & $0.7(0.3-1.6)$ & 0.433 & $0.9(0.3-2.8)$ & 0.884 \\
\hline & $41-50$ & $0.3(1.4-0.5)$ & $<0.001$ & $0.6(0.2-1.7)$ & 0.310 \\
\hline & $51-60$ & $0.3(0.2-0.6)$ & $<0.001$ & $0.5(0.2-1.6)$ & 0.250 \\
\hline \multirow[t]{2}{*}{ Gender } & Male & Reference & & Reference & \\
\hline & Female & $0.8(0.5-1.2)$ & 0.210 & $0.8(0.4-1.4)$ & 0.386 \\
\hline \multirow[t]{4}{*}{ Education } & No formal & Reference & & Reference & \\
\hline & Primary & $0.7(0.3-1.7)$ & 0.485 & $0.6(0.2-1.8)$ & 0.380 \\
\hline & Secondary & $3.2(1.4-7.0)$ & 0.004 & $1.8(0.6-5.7)$ & 0.320 \\
\hline & Tertiary & $7.8(1.9-32.3)$ & 0.005 & $1.7(0.1-20.6)$ & 0.662 \\
\hline \multirow[t]{4}{*}{ Income } & $<\mathrm{R} 500$ & Reference & & Reference & \\
\hline & R500-R1 399 & $1.5(0.8-2.9)$ & 0.230 & $1.4(0.6-3.1)$ & 0.382 \\
\hline & R1 400-R10 000 & $2.0(1.0-4.1)$ & 0.050 & $0.7(0.3-1.8)$ & 0.523 \\
\hline & $>\mathrm{R} 10000$ & $1^{\mathrm{a}}$ & & $1^{a}$ & \\
\hline \multirow[t]{2}{*}{ Knowledge } & Poor & Reference & & & \\
\hline & Good & $7.4(4.6-11.7)$ & $<0.001$ & $5.8(3.1-10.6)$ & $<0.001$ \\
\hline
\end{tabular}

apredicts good practice perfectly and therefore was not included in the study. 
attitude-practice consistency. ${ }^{26}$ Education of patients on antibiotics is therefore important as it can result in positive attitudes and practices regarding antibiotics.

An important limitation of this study is that patients' practices were based on patients' responses, and not measured objectively. The cross-sectional nature of this study precludes any assumptions on the causal relationship between the factors associated with patients' knowledge, attitude and practice concerning antibiotic use. The study was conducted in a single hospital and the results may not be generalisable to patients in other areas of KwaZulu-Natal or South Africa.

\section{Conclusion}

There are important areas of deficiency in patients' knowledge, attitude and practice as regards antibiotic use. Doctors, nurses and pharmacists each have a role in the counselling of patients on correct antibiotic practices. Patients and the general public are important parts of antibiotic stewardship and there needs to be greater emphasis on educating patients and the general public on antibiotics, including the health and economic risks of antibiotic resistance.

Disclosure statement - No potential conflict of interest was reported by the authors.

Funding - There was no funding used in this research.

\section{ORCID}

K Ramchurren (1) http://orcid.org/0000-0001-9672-1213

Y Balakrishna (D) http://orcid.org/0000-0001-6449-3260

S Mahomed (D) http://orcid.org/0000-0001-7095-9186

\section{References}

1. Laxminarayan $R$, Duse $A$, Wattal $C$, et al. Antibiotic resistance-the need for global solutions. Lancet Infect Dis. 2013;13(12):1057-1098.

2. The South African Pharmacy Council. Antibiotic resistance threatens lives. Pretoria, South Africa. 2012 [cited 2016 Sep]. Available from: http://www.pharmcouncil.co.za/D_NewsPublic.asp

3. World Health Organization. What is antimicrobial resistance. Geneva, Switzerland; 2017 [cited 2018 Mar]. Available from: http://www.who. int/features/qa/75/en/

4. World Health Organization. Antimicrobial resistance: global report on surveillance. Geneva, Switzerland; 2014. [cited 2016 Sep]. Available from: http://apps.who.int/iris/bitstream/10665/112642/1/978924156 4748_eng.pdf

5. Brink A, Coetzee J, Clay C, et al. The spread of carbapenem-resistant enterobacteriaceae in South Africa: risk factors for acquisition and prevention. S Afri Med J. 2012;102(7):599-601.

6. Mendelson M. The South African antimicrobial resistance framework Cape Town. University Of Cape Town; 2015 [cited 2016 Mar]. Available from: http://www.globalhealthdynamics.co.uk/wpcontent/uploads/2015/06/08_Mendelson-Matsotso.pdf

7. Antimicrobial Resistance National Strategy Framework 2014-2024. In: Health, editor. Pretoria: National Department of Health; 2014 [cited 2016 Apr]. Available from: https://www.health-e.org.za/wpcontent/uploads/2015/09/Antimicrobial-Resistance-NationalStrategy-Framework-2014-2024.pdf
8. Okeke IN, Lamikanra A, Edelman R. Socioeconomic and behavioral factors leading to acquired bacterial resistance to antibiotics in developing countries. Emerg Infect Dis. 1999;5(1):18-27.

9. Björkman I, Erntell $M$, Röing $M$, et al. Infectious disease management in primary care: perceptions of GPs. BMC Family Pract. 2011;12(1):1-8.

10. Shehadeh M, Suaifan G, Darwish RM, et al. Knowledge, attitudes and behavior regarding antibiotics use and misuse among adults in the community of Jordan. A pilot study. Saudi Pharm J. 2012;20(2):125-133.

11. Oh AL, Hassali MA, Al-Haddad MS, et al. Public knowledge and attitudes towards antibiotic usage: a cross-sectional study among the general public in the state of penang, Malaysia. J Infect Dev Ctries. 2010;5(5):338-347.

12. Awad Al, Aboud EA. Knowledge, attitude and practice towards antibiotic use among the public in Kuwait. PloS One. 2015;10(2):1-15.

13. McNulty CA, Boyle P, Nichols T, et al. Don't wear me out--the public's knowledge of and attitudes to antibiotic use. J Antimicrob Chemother. 2007;59(4):727-738.

14. World Health Organization. Overcoming antimicrobial resistance. Geneva: World Health Organization; 2000 [cited 2017 Feb]. Available from: http://apps.who.int/iris/handle/10665/66672

15. Butler CC, Rollnick S, Pill R, et al. Understanding the culture of prescribing: qualitative study of general practitioners' and patients' perceptions of antibiotics for sore throats. Br Med J. 1998;317(7159):637-642.

16. Pereko DD, Lubbe MS, Essack SY. Public knowledge, attitudes and behaviour towards antibiotic usage in Windhoek, Namibia. S Afri J Infect Dis. 2015;30(4):134-137.

17. Royer S, DeMerle K, Dickson R, et al. Shorter versus longer courses of antibiotics for infection in hospitalized patients: a systematic review and meta-analysis. J Hosp Med. 2018;13(5):336-342.

18. Li JZ, Winston LG, Moore DH, et al. Efficacy of short-course antibiotic regimens for community-acquired pneumonia: a meta-analysis. Am J Med. 2007;120(9):783-790.

19. Scalera NM, File Jr TM. How long should we treat communityacquired pneumonia? Curr Opin Infect Dis. 2007;20(2):177-181.

20. Centers for Disease Control and Prevention. Mission critical: preventing antibiotic resistance; 2014 [cited 2017 Sep]. Available from: http:// www.mahoninghealth.org/health/mission-critical-preventingantibiotic-resistance-cdc-features-2/

21. Llewelyn MJ, Fitzpatrick JM, Darwin E, et al. The antibiotic course has had its day. Br Med J. 2017;358:j3418.

22. Abu Taha A, Abu-Zaydeh A, Ardah R, et al. Public knowledge and attitudes regarding the use of antibiotics and resistance: findings from a cross-sectional study among Palestinian adults. Zoonoses Public Health. 2016;63(6):449-457.

23. You J, Yau B, Choi K, et al. Public knowledge, attitudes and behavior on antibiotic use: a telephone survey in Hong Kong. Infection. 2008;36(2):153-157.

24. Gottfredson LS, Deary IJ. Intelligence predicts health and longevity, but why? Curr Dir Psychol Sci. 2004;13(1):1-4.

25. Hansen DL, Derry HA, Resnick PJ, et al. Adolescents searching for health information on the internet: an observational study. J Med Internet Res. 2003;5(4):1-10.

26. Fabrigar LR, Petty RE, Smith SM, et al. Understanding knowledge effects on attitude-behavior consistency: The role of relevance, complexity, and amount of knowledge. J Pers Soc Psychol. 2006;90 (4):556-577.

27. Davidson AR. From attitudes to actions to attitude change: The effects of amount and accuracy of information. In: Petty $R E$, Krosnick JA, editors. Ohio State University series on attitudes and persuasion, Vol 4. Attitude strength: Antecedents and consequences. 1995:315-336. Hillsdale, NJ, US: Lawrence Eribaum Associates.

Received: 5-12-2017 Accepted: 23-08-2018 